\title{
The urban knowledge economy and employment growth: a spatial structural equation modeling approach
}

\author{
Frank G. van Oort • Johan H. L. Oud • Otto Raspe
}

Received: 16 June 2008 / Accepted: 3 March 2009 / Published online: 26 March 2009 (C) The Author(s) 2009. This article is published with open access at Springerlink.com

\begin{abstract}
Many European governments have been stimulating their urban economies by focusing on knowledge economy potentials of metropolitan regions, especially R\&D-based indicators. We analyze employment growth in terms of conventional determinants-investments, wages, income, and specialization indices of industrial, distribution and business services activities - and three latent knowledge economy components (density of knowledge workers, R\&D and innovativeness) for the Netherlands based on a sample of 496 municipalities. We apply a structural equation model (SEM) made up of a measurement model that relates the latent knowledge economy components to their observable indicators and a structural model that estimates the impacts of the determinants on employment growth. In addition to the conventional determinants and the knowledge economy components, the SEM accounts for spatial spillover effects, degree of urbanization and core-periphery dichotomy. The latent variables 'density of knowledge workers' and 'innovativeness' have significant and strong impacts. Since they are more common in larger than smaller urban agglomerations, we conclude that the impacts of these variables on employment growth are stronger in the former than the latter. The latent variable 'R\&D-intensity' is not significantly, positively related to urban employment growth. This suggests that policy should emphasize innovation output and knowledge workers density rather than R\&D to capture urban growth potentials in the knowledge economy.
\end{abstract}

JEL Classification $\mathrm{O} 31 \cdot \mathrm{R} 12 \cdot \mathrm{R} 15 \cdot \mathrm{R} 58$

F. G. van Oort $(\varangle)$

Department of Economic Geography, Utrecht University, Utrecht, The Netherlands

e-mail: f.vanoort@geo.uu.nl

J. H. L. Oud

Radboud University Nijmegen, Nijmegen, The Netherlands

O. Raspe

Netherlands Environmental Assessment Agency, The Hague, The Netherlands 


\section{Introduction}

In 2002, the European Union (EU) set itself a strategic goal for the next decade: to become the most competitive and dynamic knowledge-based economy in the world (EU Lisbon Agreement 2000). Although the goal itself is beyond dispute, there is substantial uncertainty and confusion about its realization. This despite the fact that the knowledge economy as an engine for economic and employment growth has been analyzed in detail in the recent (economic) literature (see, amongst others, Dosi 1988; Drennan 2002; Foray 2004; Warsh 2006).

The literature on the knowledge economy, particularly the diffusion of knowledge, emphasizes its urban character (Glaeser et al. 1992; Lucas 1993). The rationale is that if knowledge is important to innovation and growth, its impact increases by degree of agglomeration because in larger urban agglomerations many economic, social and cultural activities and actors are concentrated in a relatively small geographic space so that knowledge transmits more easily.

This article has two objectives. First, it presents an empirical analysis of the major components of the knowledge economy. Second, in a bid to shed light on the importance of the knowledge economy for regional economic development, we estimate a municipal employment growth model for the Netherlands in terms of conventional determinants and knowledge economy determinants.

We observe that the notion 'knowledge economy' is a latent variable and thus not directly observable. Therefore, observable indicators are needed to measure it. For that purpose, we apply a structural equation model (SEM) with latent variables. A SEM is composed of a measurement part which represents the relationships between the latent variables and their observable indicators and a structural part that depicts the (causal) relationships between the variables (see, amongst others, Jöreskog and Sörborn 1996, for details).

Regarding the knowledge economy various definitions and measurements have been adopted. For instance, the OECD strongly emphasizes research and development (R\&D) in its definition, that is reflected in the selection of nearly 60 indicators among which $R \& D$ and high-tech related indicators are the dominant ones (OECD 2003; Godin 2004). The OECD definition thus has an industrial and technological bias and so has The Lisbon Agreement which is based on the OECD definition. Therefore, we adopt a broader perspective on the knowledge economy, to account for the fact that regional economies also benefit from other knowledge aspects than R\&D investments. For instance, innovation is considered to be an important component of the knowledge economy (Feldman 1994). Since innovation is not only related to R\&D but also requires that the market accepts new products or processes, a knowledge economy indicator reflecting innovation should be included in the analysis addition to the R\&D-indicator (Acs and Varga 2002). Further, in addition to conventional technical procedures, manufacturing and services tend to be based more and more on creative and communicative inputs (Hall 2000). Particularly, technological development has become increasingly dependent on the co-operation among actors in production and on customer networks (Clement et al. 1998). This implies that investments in human and creative capital and in communication 
networks have also become important aspects of the knowledge economy (Black and Lynch 2001). ${ }^{1}$

To account for the above aspects of the knowledge economy we consider the following three dimensions of the knowledge economy: R\&D-used in most empirical studies, density of knowledge workers (reflecting characteristics and abilities of the labor force), and innovation (output of amongst others R\&D and density of knowledge workers). We estimate their impacts on municipal employment growth in the tradition of inter aliis Glaeser et al. (1992) and Henderson et al. (1995). In this tradition, economic externalities are expected to facilitate innovation, as knowledge and technologies from different sectors are (re)combined-using amongst others human and creative capital-leading to new products or technologies. When innovations lead to the creation of new products and markets this will lead to employment growth (Saviotti and Pyka 2004).

The empirical analysis for the Netherlands is based on observations on municipal communities. This implies that spatial dependence should be explicitly taken into account, because spatial dependence on this low spatial scale is to be expected. Particularly, employment growth in one municipality is likely to be dependent on and to influence employment growth in municipalities nearby (spatial lag). This applies especially to urban areas where average commuting distance extends well into municipalities beyond the city borders (Van Oort 2004).

Another feature of the spatial structure that we explicitly take into account is the core-periphery dichotomy. The core or Randstad is the urban conurbation in the western part of the Netherlands, in which the four major cities (Amsterdam, Rotterdam, The Hague and Utrecht) and a number of smaller towns are located within close proximity to each other (see Fig. 1). The name, (including the Dutch word "stad" for "city' (in the singular)), suggests that the Randstad is a single, contiguous urban region. From the 1960s onwards, the Randstad has been internationally regarded as one of the most important clusters of economic activities in Europe (Hall 1966). It is a readily accessible network of cities and locations which, given their mutually dependent specializations and complementary service and production activities, create a favourable setting for economic activities. The Randstad forms the heart of the Dutch economy, where some $50 \%$ of the gross national product is generated on approximately $25 \%$ of the country's total land area (Van Oort et al. 2008). It is generally assumed that the towns and cities complement each other in terms of economic specializations that make them more competitive than they would be in isolation (Batten 1995; Camagni and Capello 2004).

A second (separate) feature of the spatial structure we take into account is whether or not municipalities are connected to an urban center by commuting relations. Municipalities connected to an urban center are assumed to benefit from the employment growth stimulating characteristics of these centers. Moreover, suburban municipalities in the vicinity of urban centers are likely to benefit from employment spillovers from the urban centers.

\footnotetext{
1 Recent overviews of these theories and their spatial impacts can be found in Surinach et al. (2007) and Capello and Nijkamp (2004).
} 


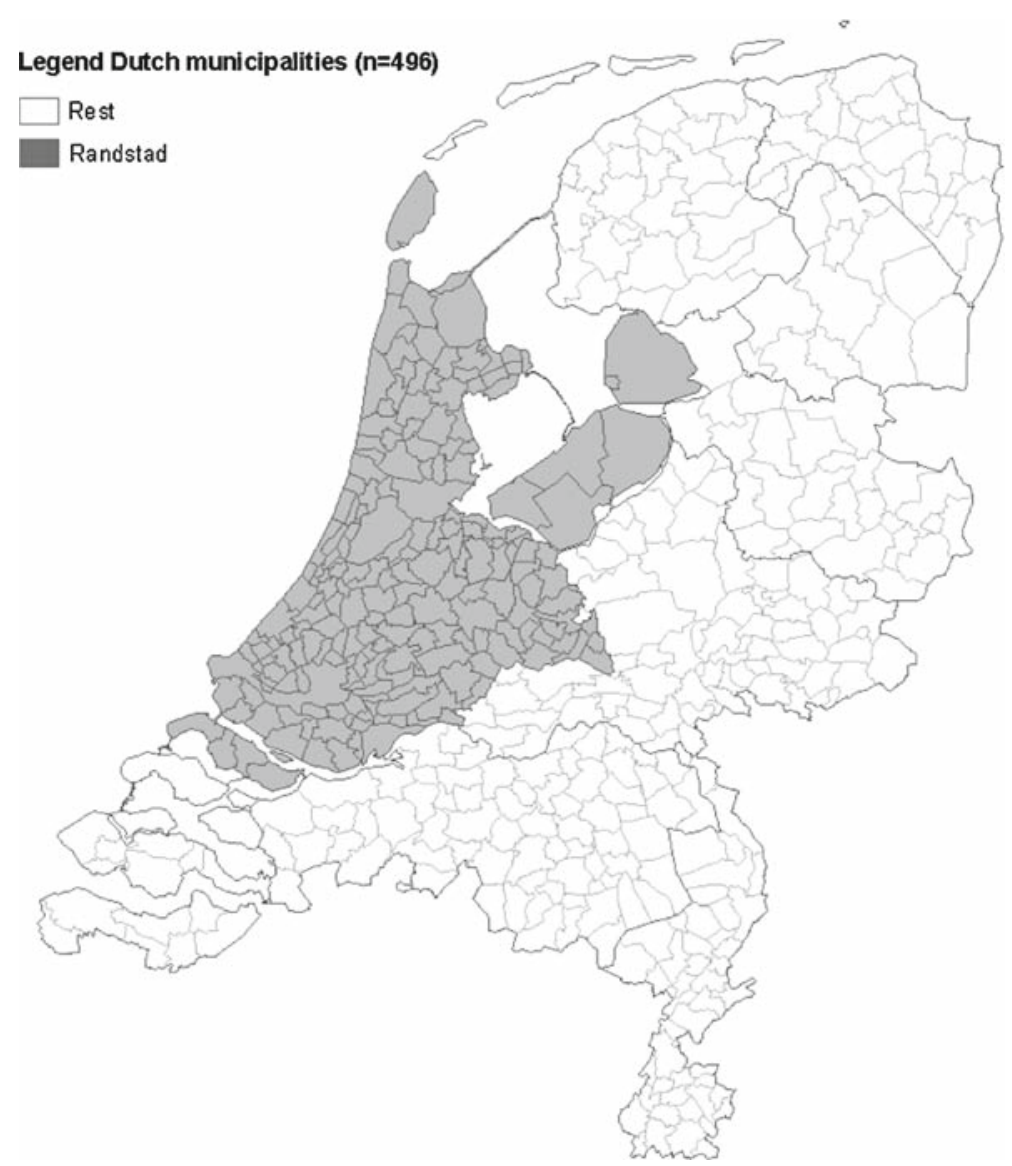

Fig. 1 National zoning spatial regimes ('Randstad')

This article is organized as follows. Section 2 briefly reviews the literature on the knowledge economy in a bid to identify the main knowledge economy indicators and their impacts on employment growth. In this section we also pay attention to the spatial setting, particularly knowledge spillovers in a spatial context. Section 3 discusses the data and spatial SEM as well as the other determinants of the municipal employment. The empirical results are presented in Sect. 4. Section 5 concludes and presents some policy recommendations.

\section{Indicators of the knowledge economy in a spatial framework}

The recent interest in and discussion of the knowledge economy is embedded in a long tradition. During the sixties of the twentieth century the term 'knowledge economy' was introduced by Machlup (1962) and Drucker (1959). It is usually understood as an economy in which the production factors labor and capital are aimed at the development and application of new technologies (OECD 2003). This definition falls short in 
two respects. First, it does not define knowledge, and, second, the ultimate goal of the knowledge economy is taken to be the application of new technologies as such while, in fact, the application is instrumental to the ultimate goals of economic and employment growth. Since its introduction, many theoretical and empirical contributions have refined and broadened the concept. We shall briefly discuss this literature in a bid to distill (measurable) indicators from it that are relevant for a municipal employment growth model.

In analyzing spatial effects of knowledge on employment growth, it is necessary to first take a look at the role of knowledge and knowledge transmission in organizations. Knowledge relevant to organizations can be obtained by experience, science or learning (Foray 2004). As observed in the preceding section, knowledge may lead to innovation: the commercial exploitation of knowledge. For our purposes we define knowledge as the ability to recognize and solve problems, by collecting, selecting and interpreting relevant information. Hence, a basic feature of the knowledge economy is the use of knowledge in interrelationships among market actors to produce goods and services, from the first idea to final products (Raspe and Van Oort 2006).

Below we discuss the main components of the knowledge economy that have been shown to be relevant for employment growth. Before going into detail we observe that most of the variables discussed below directly or indirectly-via economic growthimpact upon employment growth. Due to lack of data on economic growth at the level of municipalities we opt for a reduced form approach in the sense that we directly regress employment growth on the knowledge economy components (and the other explanatory variables).

Lucas (1988) and Mathur (1999) argue that human capital, particularly education, is a crucial feature of the knowledge economy. A well-educated workforce has ample opportunities to absorb and use information. Firms endowed by a well-educated workforce have been found to be relatively competitive (Mathur 1999; Bates 1990). Therefore, we take the average educational level of the working population per municipality as our first indicator. Glaeser and Saiz (2003) show that a well-educated labor force is more likely to be found in urban centers than in rural regions, which justifies the inclusion of this variable in our municipal employment growth model.

Florida (2002) identifies creative capital embodied in knowledge workers and artists as a major indicator of the knowledge economy. The difference between human and creative capital is that the "creative class" (as Florida labels it) need not necessarily have a high educational level in order to create more than average added value. In addition to direct productivity effects produced by knowledge workers, Florida emphasizes indirect growth effects from consumption by the creative class in the amenity-rich urban environments they live. Since data on the creative class itself is not available, we follow Florida and resort to a proxy, i.e., the density of creative industries in which creative capital is employed (see Raspe and Van Oort 2006) as the second knowledge economy indicator.

The literature on the knowledge economy also emphasizes two indicators that reflect accessibility and transfer of knowledge. Particularly, Drennan (2002) and Black and Lynch (2001) analyze the growth potentials of firms and their resulting demand for labor due to increased accessibility of information through the adoption of information- and communication technologies (ICT) in their operations. These authors show 
that ICT functions as an important vehicle of knowledge transfer when information is codified. Hence, we take ICT density (measured by municipal computer usage per employee per 5-digit industry) as third indicator.

Cooke and Morgan (1998) and Clement et al. (1998) identify social, cultural and communicative capital as sources of employment growth. Van der Laan et al. (2006) measure this variable via a proxy, i.e., the classification of occupations according to the degree of communicative skills needed for interaction (as suggested by McCloskey and Klamer (1995)). Following Van der Laan et al. (2006), we define the average degree of communication skills per category of occupations per municipality weighted by the total labor force for that category as fourth indicator. Observe that the present indicator is closely related to creative and human capital and ICT-density. We shall return to this issue below.

Our definition of the knowledge economy also addresses technical and production oriented aspects. As shown by amongst others Black (2004), traditionally most attention has been paid to research and development (R\&D) in this context. This also holds for policymakers because $R \& D$ can be stimulated by policy handles, particularly subsidies (Acs 2002). We use the share of R\&D employees as fifth indicator.

Cortright and Mayer (2001) emphasize the role of high- and medium tech firms as indicators of the knowledge economy and drivers of economic and employment growth. Therefore, in this study we take the density of high- and medium tech industries relative to the total population of firms as sixth indicator.

$\mathrm{R} \& \mathrm{D}$ is an input into the development of innovation, which is generally regarded as the most important driver of economic and employment growth. Several indicators of innovation exist, like new product announcements, publications, patents and firm selfratings (Jaffe and Trajtenberg 2002). In this article, we use firm self-ratings in terms of new products and processes (the CIS3-questionnaire for the Netherlands, see Raspe and Van Oort 2006). We distinguish between technical and non-technical innovations. While technical innovations relate to new products and production processes, nontechnical innovations concern management, organization and services. Both aspects are taken into account as the proportion of innovative firms in a municipality. They are the seventh and eighth indicators.

The above-introduced variables are indicators of underlying latent variables and therefore are strongly correlated. Direct inclusion of the indicators would lead to high multicollinearity and hence an increase of the estimated variances of the estimators of their coefficients, so that one might be led to drop some of them incorrectly from the employment growth model. Therefore, we include the latent variables into the structural model rather than the indicators so as to substantially reduce the multicollinearity problem (Oud and Folmer 2008).

The latent variables are related to their observable indicators via a measurement model. We distinguish the following latent variables

1. 'R\&D' with indicators: the density of high and medium tech firms and the share of R\&D employees

2. 'Knowledge workers' with indicators: ICT sensitivity, educational level, creative class, and communicative skills

3. 'Innovativeness' with indicators: technical and non-technical innovations. 
In addition to the knowledge economy, we include various other variables in the model that have been identified as major determinants of employment growth. Specifically:

- Investments ${ }^{2}$ that are assumed to have a positive impact if they are complementary to employment but a negative effect if they substitute labor.

- Wages ${ }^{3}$ and income as indicators of demand; they are assumed to positively impact on employment growth.

- The above average availability of industrial sites to accommodate firm locations; we expect a positive impact ${ }^{4}$.

- Finally, we consider specialization indices of industrial, distribution and business services activities. Specializations in industrial activities, distribution activities and business services are assumed to have positive impacts on localized employment growth because of clustering effects leading to economies of scale and scope (Rosenthal and Strange 2004).

Although employment growth models have been specified in terms of both levels and changes of the explanatory variables (McCann 2004), few attempts have been made to empirically analyze several of the above mentioned control variables in terms of changes. In this article, we test the dynamic specification of the wage-, income- and investment variables since it more accurately captures employment dynamics than the static specification (Henderson 1997; Glaeser and Maré 2001).

A large and growing empirical literature analyzes knowledge externalities and their relevance for innovation and employment growth in a spatial setting. Audretsch and Feldman (1999) and Jaffe and Trajtenberg (2002), amongst others, show that spatial proximity (clustering) is important to explaining localized growth in knowledge-intensive industries. The rationale is that the marginal cost of transmitting tacit knowledge rises with distance. As tacit knowledge and human interaction become more valuable in innovation processes, geographical proximity becomes crucial to innovation and employment growth.

Most of the present empirical literature focuses on US states as the spatial unit of analysis (Feldman 1994). Some research, however, focuses on lower spatial scales of analysis. Anselin et al. (2000); Wallsten (2001) and Black (2004), for instance, analyze the spatial extent of $R \& D$, innovation (patents) and growth externalities in the US metropolitan areas and find that local spatial externalities are present and important. Jaffe et al. 1993) also find that proximity matters in the transmission of knowledge and of innovations and that distance decay tends to be rather steep. For the Netherlands Van Oort (2004) and Thissen (2005) suggest that employment growth spillovers may well reach beyond the geographic definition of spatial units, although little is known

\footnotetext{
2 Concerning investments in immobile capital goods, excluding housing.

3 The traditional expectation is that low wage levels attract investment, and by doing so, enhance employment growth. A positive relation between wage levels and employment growth is also not uncommon though (Kleinknecht 1999), This latter outcome may reflect the higher human capital levels in high-wage regions. High wages may also act as a trigger to migrate, and by doing so, raise employment/supply of labor (compare Broersma and van Dijk 2002).

4 Measured in acres to the employment base.
} 
about their exact spatial extent. The foregoing implies that spatial dependence needs to be taken into account. In the empirical analysis this will be done by means of a spatial lag model in which employment growth in a given municipality is related to employment growth in neighboring regions.

Anselin et al. (2000) and Parr (2005), amongst others, have shown that core and urban regions offer important benefits for knowledge intensive firms, particularly an amenity rich environment and good communication possibilities. Therefore, we expect the impacts of the knowledge components on municipal employment growth to be stronger in the core and urban municipalities than in the periphery and rural areas. For the other explanatory variables we expect less outspoken differences. In the empirical analysis the core periphery dichotomy will be taken into account by estimating different submodels for municipalities in the Randstad and municipalities not in the Randstad (see Sect. 1 for details about the Randstad). Regarding the urban-rural regime we follow Van Oort (2004) who defines an urban conglomerate as being made up of one or more cities and their neighboring municipalities that are within commuting distance. ${ }^{5}$ Figure 2 shows that the urban areas need not be contiguous, although most of them are, particularly in the Randstad.

\section{Data and spatial SEM}

As mentioned in the preceding section, we empirically analyze municipal employment growth in terms of conventional determinants and latent knowledge economy components measured in terms of eight knowledge-economy indicators for sample of 496 municipalities. Table 1 presents descriptive statistics of all observed variables used in the analysis. ${ }^{6}$

Economic growth for the period 1996-2003 is measured in logarithms of growth in employment in the period 1996-2003. Similarly for income growth, wage growth and investment growth taking into account inflation are defined in the same manner. All three variables are measured in actual monetary values. The level specifications concern the begin-of-period situation (1996). Specializations in industrial activities, distribution activities and business services are introduced as location quotients, measuring the relative over- or under representation of these sectors in municipalities compared to their national shares.

As mentioned in the preceding section, the municipal employment growth model contains latent variables and corresponding observables. In order to estimate the impacts of the latent variables on employment growth and simultaneously the relationships among the latent variables and their observable indicators we make use of a SEM with latent variables. A SEM is made up of a latent variables measurement model and a structural model that are estimated simultaneously (see, amongst others, Jöreskog and Sörborn 1996). Several estimators for SEMs have been developed

\footnotetext{
5 Urban core municipalities have an important employment function. More than 15,000 persons commute into these municipalities (while living somewhere else) on a daily basis. Municipalities where more than $20 \%$ of residents commute to central core locations are labelled suburban.

6 Maps of the knowledge-economic indicators can be found in Raspe and Van Oort (2006).
} 


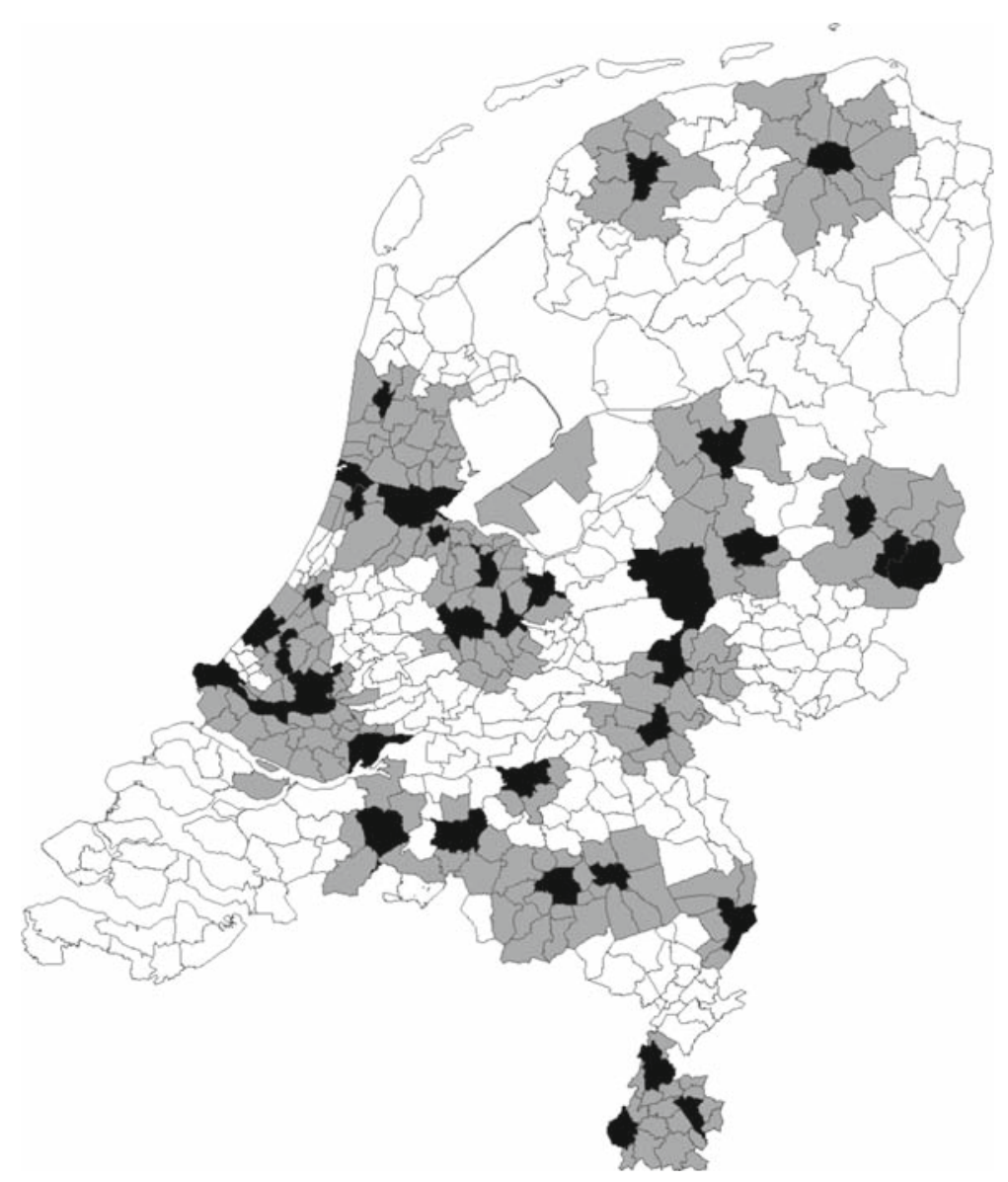

Fig. 2 The labor market urban regimes ('connectedness')

including instrumental variables, two-stage least squares, unweighted least squares, fully weighted least squares, diagonally weighted least squares and maximum likelihood. These estimators are available in the software packages Mx (Neale et al. 2003) and LISREL 8 (Jöreskog and Sörborn 1996). These packages also include procedures to check model identification, to evaluate the estimation results and to calculate indirect and total effects.

A standard SEM is based on the assumption of independent observations. Due to spillover effects, this assumption does usually not hold for spatial data. Particularly, for the spatial lag model we need to take into account that the spatial lag variable is a transformation of the dependent variable and therefore cannot be assumed to be uncorrelated with the error term. Oud and Folmer (2008) correct the standard SEM likelihood function to account for spatial dependence in the lag model such that the resulting estimator is consistent and unbiased. The spatial dependence corrected maximum likelihood estimator is applied below. 
Table 1 Descriptive statistics of the variables

\begin{tabular}{|c|c|c|c|c|}
\hline & Mean & $\begin{array}{l}\text { Standard } \\
\text { deviation }\end{array}$ & Minimum & Maximum \\
\hline Education level $^{\mathrm{a}}$ & 1.92 & 0.08 & 1.76 & 2.21 \\
\hline Creative industry $^{\mathrm{c}}$ & 2.03 & 1.58 & 0.26 & 20.84 \\
\hline ICT-density $^{\mathrm{b}}$ & 0.75 & 0.11 & 0.53 & 1.27 \\
\hline Communicative skills ${ }^{\mathrm{d}}$ & 0.53 & 0.08 & 0.33 & 0.80 \\
\hline$R \& D^{f}$ & 2.81 & 1.09 & 1.00 & 5.00 \\
\hline High-tech and medium-tech firms ${ }^{\mathrm{e}}$ & 7.70 & 4.69 & 0.00 & 27.00 \\
\hline Technical innovation ${ }^{\mathrm{h}}$ & 3.00 & 1.40 & 1.00 & 5.00 \\
\hline Non-technical innovation ${ }^{\mathrm{h}}$ & 3.00 & 1.38 & 1.00 & 5.00 \\
\hline Industrial specialization & -0.38 & 0.32 & -1.56 & 0.57 \\
\hline Distribution specialization & 0.04 & 0.17 & -0.57 & 0.43 \\
\hline Producer services specialization & -0.16 & 0.19 & -0.71 & 0.43 \\
\hline Investment level 1996 & 7.69 & 0.44 & 5.89 & 9.22 \\
\hline Change investment level 1996-2003 & 0.14 & 0.09 & -0.22 & 0.54 \\
\hline Wage level 1996 & 4.39 & 0.69 & 4.19 & 4.65 \\
\hline Change wage level 1996-2003 & 1.33 & 0.55 & -0.09 & 0.36 \\
\hline Income level 1996 & 1.23 & 0.04 & 1.15 & 1.38 \\
\hline Change income level 1996-2003 & 0.10 & 0.01 & 0.03 & 0.15 \\
\hline Supply of business areas 1996-2003 & 0.09 & 0.16 & -0.48 & 0.82 \\
\hline Employment growth 1996-2003 & 0.06 & 1.12 & -2.62 & 5.89 \\
\hline
\end{tabular}

$n=496$ (Dutch municipalities)

a The education level is the weighted average (respectively with the weights: 1,2,3) of the educational levels: high (university and higher vocational education), middle (intermediate vocational education, higher general secondary education and pre-university education) and low (lower general secondary education and lower vocational education). This indicator is frequently used and represents the average regional level of education (Broersma and Oosterhaven 2005)

$\mathrm{b}$ The indicator measures the number of computers and terminals per employee on the level of a municipality, using computerization data from Statistics Netherlands and the LISA-file on firms and employment

c Based on Raspe and Van Oort (2006)

d Based on the classification by McCloskey \& Klamer (1995)

e High-tech and medium-tech firm are classified by their (detailed) SIC codes by their extend of research and export orientation, see OECD (2003)

${ }^{\mathrm{f}}$ Based on Raspe and Van Oort (2006). Data on R\&D intensity per sector per Dutch province are taken form the third Community Innovation Survey (CIS3, Statistics Netherlands), and are allocated to municipalities using the employment structure per sector in the LISA database

${ }^{\mathrm{h}}$ Based on Raspe and Van Oort (2006). Data on innovation intensity is taken from the CIS-3 questionnaire (Statistics Netherlands). Innovation is registered as products and services that are new in the market or sector

\section{Empirical results}

As a first step, we applied factor analysis to the indicators of the knowledge economy to test their relationships to the hypothesized underlying latent variables, as discussed in Sect. 2. For that purpose we used the entire sample and did not take into account the core periphery nor the urban rural regimes. The results are presented in Table 2. First, 
Table 2 Measurement model of factor loadings for the knowledge economy indicators

\begin{tabular}{|c|c|c|c|c|}
\hline \multirow[t]{2}{*}{ Indicators } & \multicolumn{3}{|l|}{ Factors } & \multirow{2}{*}{$\begin{array}{l}\text { Proportion of } \\
\text { explained } \\
\text { variance } \\
\text { (reliability) }^{\mathrm{a}}\end{array}$} \\
\hline & $\begin{array}{l}\text { Factor } 1 \\
\text { 'Knowledge } \\
\text { workers' }\end{array}$ & $\begin{array}{l}\text { Factor } 2 \\
\text { 'Innovativeness' }\end{array}$ & $\begin{array}{l}\text { Factor } 3 \\
\text { 'R\&D' }\end{array}$ & \\
\hline ICT-density & $0.757(21.3)$ & - & - & 0.573 \\
\hline Education level & $1.000(38.1)$ & - & - & 1.000 \\
\hline Creative class & $0.360(8.4)$ & - & - & 0.130 \\
\hline Communicative skills & $0.898(28.9)$ & - & - & 0.806 \\
\hline High-tech and medium-tech firms & - & - & $0.886(16.4)$ & 0.785 \\
\hline Share of R\&D employees & - & - & $0.516(10.7)$ & 0.266 \\
\hline Innovation (technical) & - & $0.954(22.1)$ & - & 0.910 \\
\hline Innovation (non-technical) & - & $0.783(17.9)$ & - & 0.613 \\
\hline
\end{tabular}

$t$ values between brackets

a Since there is only one latent variable per indicator, the reliability equals the squared (standardized) loadings

the (standardized) loadings are given, then between parentheses the standard errors. The last column gives the proportions of explained variance in the indicators by the latent variables (reliabilities of the indicators). ${ }^{7}$

The results presented in Table 2 confirm the hypotheses presented in Sect. 2. Particularly, it shows that ICT density, educational level and communicative skills are important indicators of the latent variable knowledge workers. The indicator creative class, however, has a relatively low loading. The coefficient is significant, though. The variables "technical and non-technical innovation" are significant indicators of innovativeness, the former slightly more important than the latter. Similarly, the latent $R \& D$ variable is built up by the variables R\&D-intensity and the share of high and medium tech firms, with the latter as the dominant indicator.

The spatial patterns of the knowledge economy components are presented in Figs. 3, 4, and 5. From Fig. 3, it follows that knowledge workers are concentrated in larger cities and regions in or close to the north wing of the Randstad. This applies in particular to large cities like Amsterdam and Utrecht as well as their suburban surroundings. The rural regions and de regions in de national periphery are lagging behind. The spatial distribution of 'R\&D' (Fig. 4) is quite different from that of knowledge workers. While the latter is concentrated in the western and central part of the Netherlands, $\mathrm{R} \& \mathrm{D}$ is concentrated in the southern and eastern periphery. These are the regions that have a strong industrial orientation (Van Oort 2004). The regions of Eindhoven (with Philips and ASML), Wageningen (university), Delft (university), and Dordrecht and Terneuzen (with technologically oriented multinational firms) are the R\&D hotspots in

\footnotetext{
7 Based on the assumption of spatial regimes, we estimated four different SEM models: Randstad, nonRandstad, urban and non-urban. Since the measurement models for the regimes turned out to be very similar and close to the measurement model for the entire (pooled) data set, we only present the latter in Table 3. The measurement models by regimes are available upon request.
} 


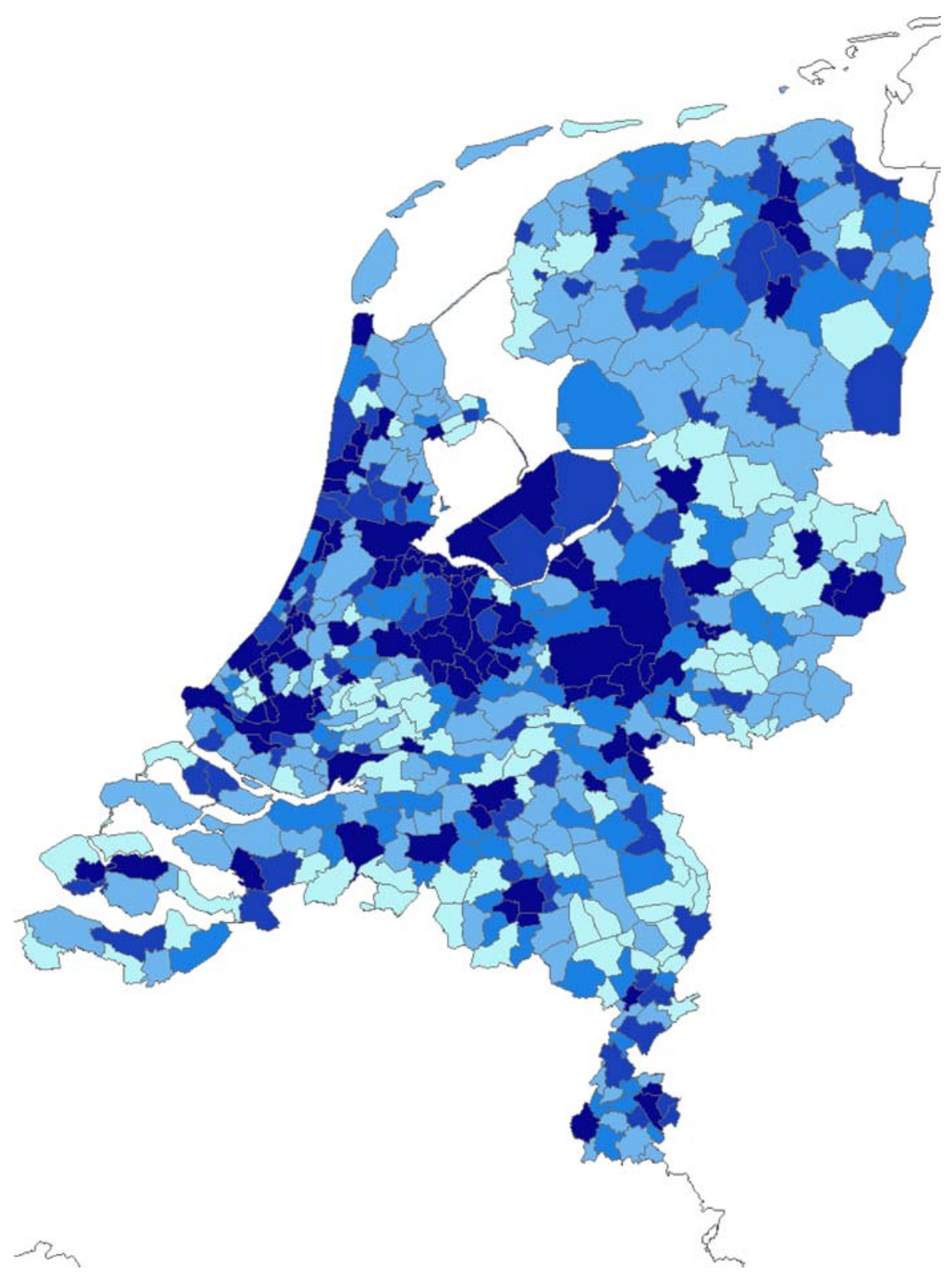

Fig. 3 The 'Knowledge workers' dimension

the Netherlands. Regarding the third factor Fig. 5 shows that innovative firms are concentrated in the Randstad, and in the eastern part of the Netherlands. The Amsterdam and Rotterdam regions are relatively innovative.

Table 3 presents the SEMs for the pooled data set, where the latent variables knowledge workers, innovativeness and R\&D are defined and simultaneously estimated in 


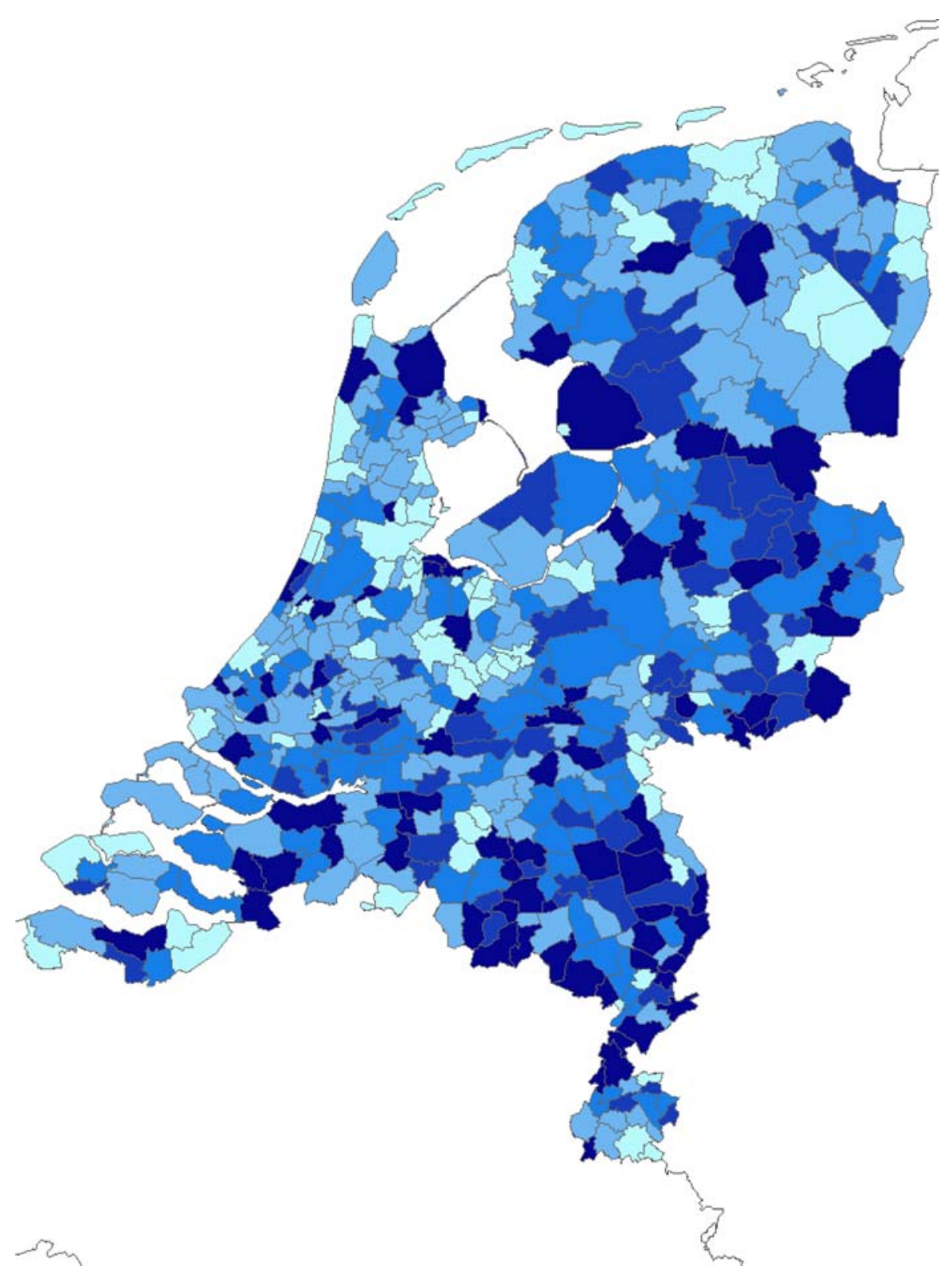

Fig. 4 The 'R\&D' dimension

the measurement model. Following Florax et al. (2003), the hypothesis of spatially uncorrelated errors was rejected in favor of a spatial lag model. All models in Table 3 therefore present the standard spatial lag model, using static and dynamic versions of the variables concerning investment and income (and a static version of wages), and differentiating coefficients over the spatial regimes of urban connectedness (columns 


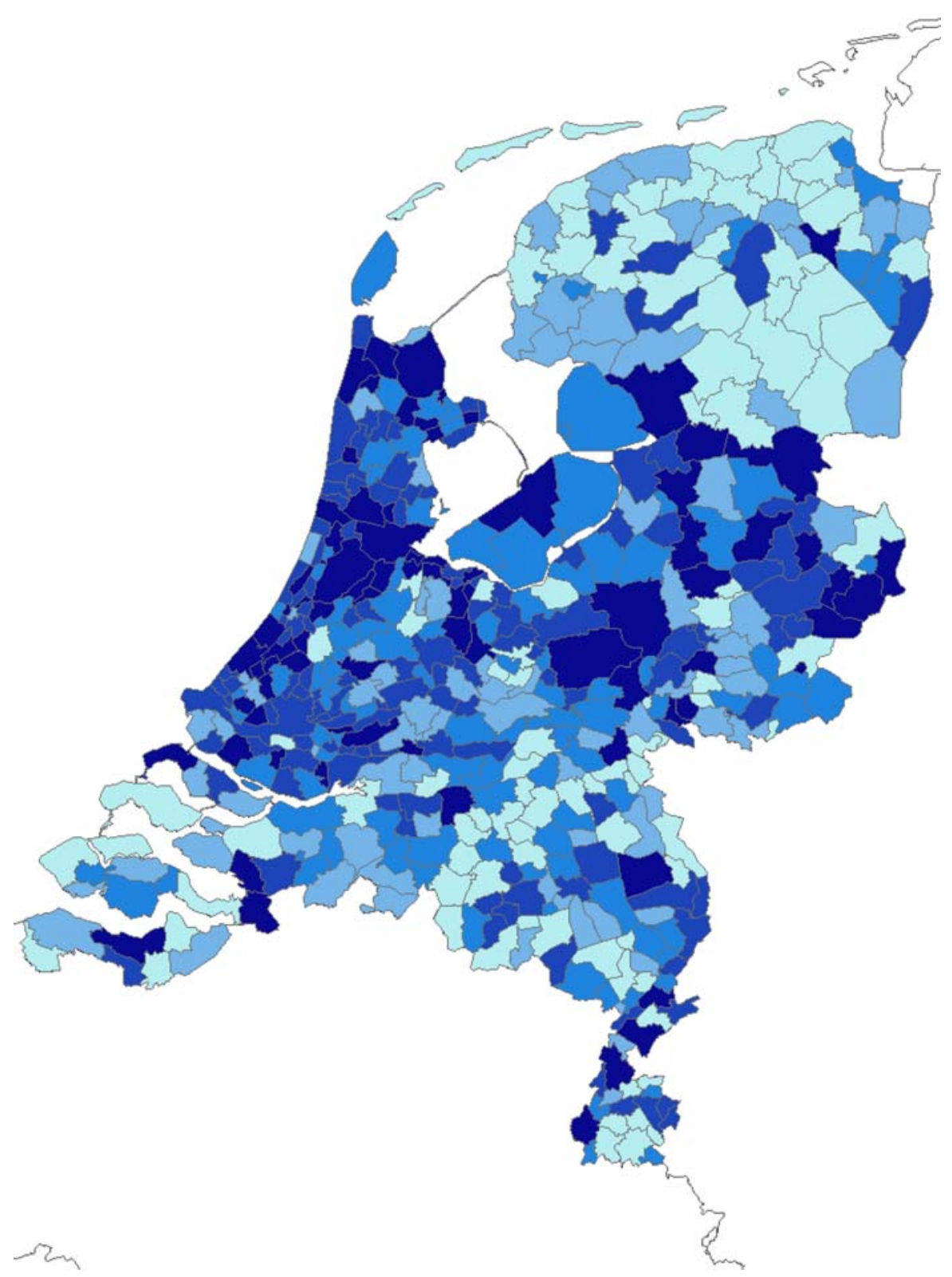

Fig. 5 The 'Innovativeness' dimension

3 and 4) and the national core-periphery (columns 5 and 6). Because of potential multicollinearity problems due to high correlations, the variables "growth in wages" and "growth in investment" are not introduced together in the models. For the same reason, level and growth versions of conventional variables are not introduced simultaneously. 


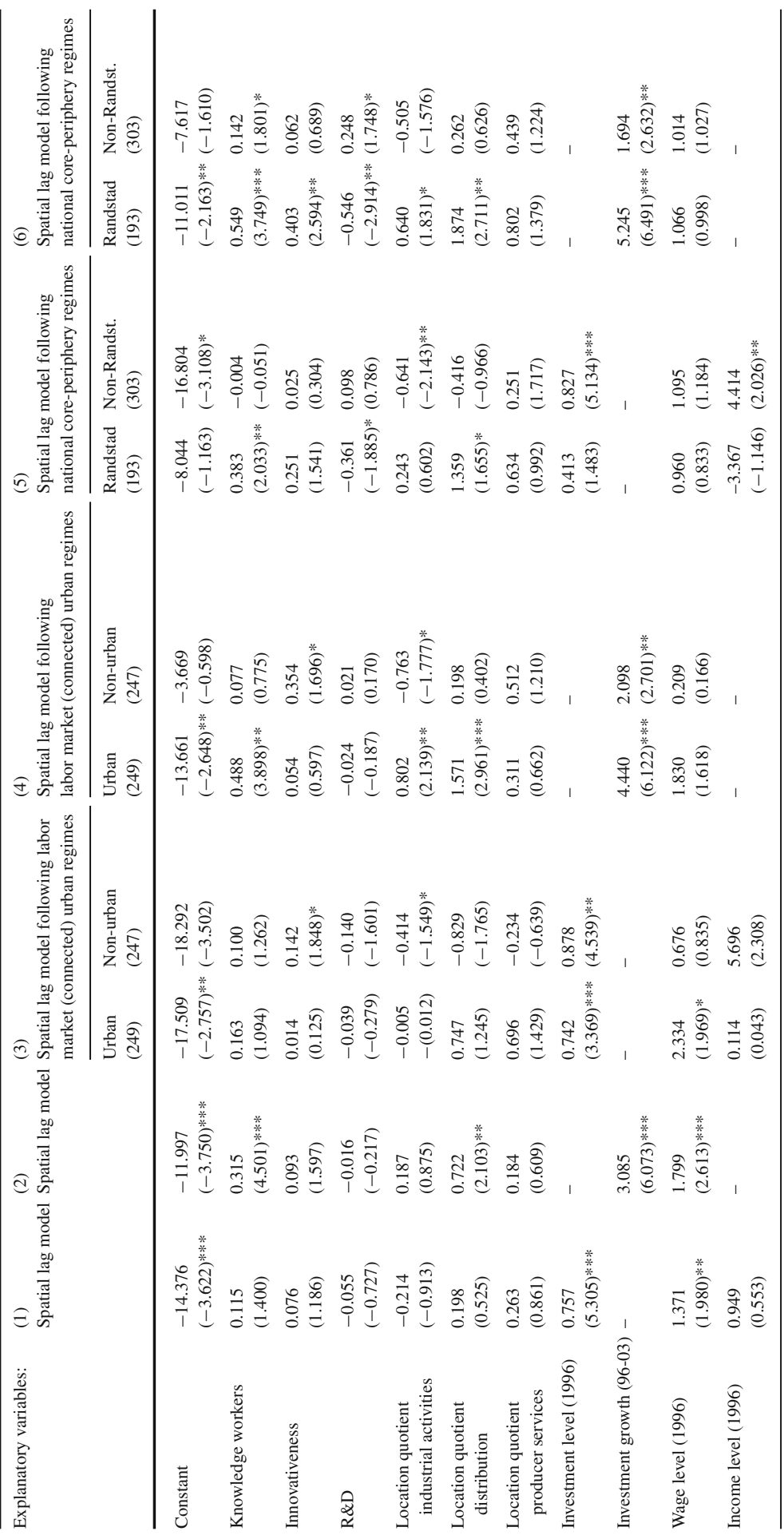




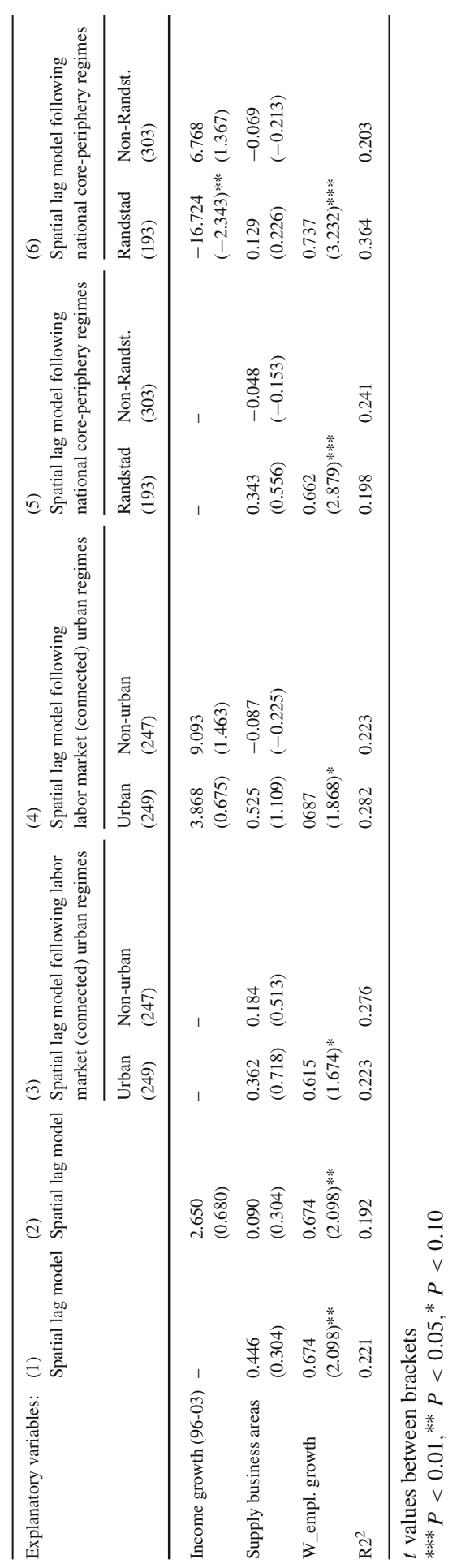


The spatial lag parameter-capturing spatial externality effects in localized employment growth-is significant in all specifications. Once we control for this spatial dependence, the knowledge economy indicators 'knowledge workers' and 'innovativeness' are most significantly and positively attached to employment growth. The knowledge workers dimension most robustly fosters growth as comes to the fore in the spatial lag model with dynamically specified investment and income control variables (column 2), the urban connectedness regime in column 4, The Randstad regime in column 5 and both core-periphery regimes in column 6 . The regime analysis shows that the attachment of the knowledge workers dimension to employment growth is significantly more common in larger than smaller urban agglomerations, and in the Randstad region as opposed to the national periphery. The innovativeness dimension shows less bias towards urbanised areas, as the relation innovativeness-growth is significant in the non-urban regimes in both columns 3 and 4. The 'innovativeness' dimension is positively attached to growth in the Randstad regime though (column 6). The R\&D dimension is negatively attached to employment growth in the Randstad regime (columns 5 and 6), and-only slightly-positively in the non-Randstad regime in column 6 . The limited positive impact of the R\&D dimension on employment growth is surprising, since the literature and policy especially stress this dimension as a precondition for growth. This suggests that policy should emphasize innovation output and knowledge workers density in urban and national core regions rather than $R \& D$ to capture growth potentials in the knowledge economy.

Coefficients of the convenient and control variables differ in magnitude and sign over the models. The 'supply of business areas' variable is never significantly attached to growth. Following earlier studies (Henderson 1997; Combes 2000) specializations in industrial and distribution activities are-when significant-positively attached to employment growth in urbanized areas (at the connectedness and Randstad level), and negatively in non-urbanized areas. Investment at the begin-of-period (1996) and growth in investments during the period of analyses are positively attached to employment growth in all specifications, indicating that investments are a very important predictor of employment. The wage level indicator has a positive impact on employment growth in the non-regime models (columns 1 and 2); over the regime specifications differences in wage structures and its relation to growth are limited (compare Broersma and Oosterhaven 2005). The income level and growth variables-introduced as indicator of demand-have no significant impact on employment growth.

\section{Conclusions}

Many European governments have been stimulating urban economies by focusing on knowledge economy potentials of metropolitan regions, especially R\&D-based indicators. We analyzed employment growth in terms of conventional determinantsinvestments, wages, income, and specialization indices of industrial, distribution and business services activities - and three latent knowledge economy components (density of knowledge workers, $\mathrm{R} \& \mathrm{D}$ and innovation) for the Netherlands based on a sample of 496 municipalities. We applied a SEM made up of a measurement model that relates the latent knowledge economy components to their observable indicators 
and a structural model that estimates the impacts of the determinants on employment growth. In addition to the conventional determinants and the knowledge economy components, the SEM accounts for spatial spillover effects, degree of urbanization and core-periphery dichotomy. The latent variables of 'density of knowledge workers' and 'innovativeness' have significant positive and strong impacts. Since they are more common in larger than smaller urban agglomerations, we conclude that the impacts of these variables on employment growth are stronger in the former than the latter. The latent variable 'R\&D-intensity' is not significantly positive related to urban employment growth. This suggests that policy should emphasize innovation output and knowledge workers density rather than R\&D to capture urban growth potentials in the knowledge economy.

Open Access This article is distributed under the terms of the Creative Commons Attribution Noncommercial License which permits any noncommercial use, distribution, and reproduction in any medium, provided the original author(s) and source are credited.

\section{References}

Acs ZJ (2002) Innovation and the growth of cities. Edward Elgar, Cheltenham

Acs Z, Varga A (2002) Introduction to the special issues on regional innovation systems. Int Reg Sci Rev 25:3-7. doi:10.1177/016001702762039358

Anselin L (1988) Spatial econometrics: methods and models. Kluwer, Dordrecht

Anselin L, Varga A, Acs ZJ (2000) Geographical and sectoral characteristics of academic knowledge externalities. Pap Reg Sci 79:435-443. doi:10.1007/PL00011486

Audretsch DB, Feldman MP (1996) R\&D spillovers and the geography of innovation and production. Am Econ Rev 86:630-640

Bates T (1990) Entrepreneur human capital inputs and small business longevity. Rev Econ Stat LXXII: 551-559. doi:10.2307/2109594

Batten D (1995) Network cities: creative urban agglomerations for the 21st century. Urban Stud 32:313-327. doi:10.1080/00420989550013103

Black G (2004) The geography of small firm innovation. Kluwer, Dordrecht

Black S, Lynch L (2001) How to compete: the impact of workplace relations and information technology on productivity. Rev Econ Stat 83(3):434-445

Broersma LJ, van Dijk J (2002) Regional labour market dynamics in the Netherlands. Pap Reg Sci 81: 343-363. doi:10.1007/s101100200126

Broersma LJ, Oosterhaven J (2005) Regional differences in labour productivity in the Netherlands. Tijdschr Econ Soc Geogr 96:334-343. doi:10.1111/j.1467-9663.2005.00464.x

Camagni R, Capello R (2004) The city network paradigm: theory and empirical evidence. In: Capello R, Nijkamp P (eds) Urban dynamics and growth. Elsevier, Amsterdam, pp 495-529

Capello R, Nijkamp P (eds) (2004) Urban dynamics and growth. Advances in urban economics. Elsevier, Amsterdam

Clement W, Hammerer G, Schwarz K (1998) Intangible capital from an evolutionary perspective. OECD, Paris

Combes PP (2000) Economic structure and local growth: France 1984-1993. J Urban Econ 47:329-355. doi:10.1006/juec.1999.2143

Cooke P, Morgan K (1998) The associational economy. Firms, regions and innovation. University Press, Oxford

Cortright J, Mayer H (2001) High-tech specialization: a comparison of high-tech centres. The Brookings Survey papers, pp 1-18

Dosi G (1988) Sources, producers and microeconomic effects of innovation. J Econ Lit 26:1120-1171

Drennan MP (2002) The information economy and American cities. The Johns Hopkins University Press, Baltimore

Drucker P (1959) Landmarks of tomorrow: a report on the new post-modern world. Harper, New York 
Feldman MP (1994) The geography of innovation. Kluwer, Dordrecht

Florax RJGM, Folmer H, Rey S (2003) Specification searches in spatial econometrics: the relevance of Hendry's methodology. Reg Sci Urban Econ 33:557-579. doi:10.1016/S0166-0462(03)00002-4

Florida R (2002) The rise of the creative class. Basic Books, New York

Foray D (2004) The economics of knowledge. The MIT Press, Cambridge

Glaeser EL, Maré DC (2001) Cities and skills. J Labor Econ 19:316-342. doi:10.1086/319563

Glaeser EL, Saiz A (2003) The rise of the skilled city. Working paper 10191. National Bureau of Economic Research, Cambridge

Glaeser EL, Kallal HD, Scheinkman JA, Shleifer A (1992) Growth in cities. J Polit Econ 100:1126-1152. doi: $10.1086 / 261856$

Godin B (2004) The new economy: what the concept owes to the OECD. Res Policy 23:679-690. doi:10. 1016/j.respol.2003.10.006

Hall P (1966) The world cities. Weidenfeld and Nicolson, London

Hall P (2000) Creative cities and economic development. Urban Stud 37:639-649. doi:10.1080/ 00420980050003946

Henderson JV (1997) Externalities and industrial development. J Urban Econ 42:47-70. doi:10.1006/juec. 1997.2036

Jöreskog KG, Sörborn D (1996) LISREL 8: user's reference guide. Scientific Software International, Chicago

Jaffe A, Trajtenberg M (2002) Patents, citations and innovation. A window on the knowledge economy. The MIT Press, Cambridge

Jaffe AB, Trajtenberg M, Henderson R (1993) Geographic localization of knowledge spillovers as evidenced by patent citations. Q J Econ 36:577-598. doi:10.2307/2118401

Lucas RE (1988) On the mechanism of economic development. J Monet Econ XXII:3-42. doi:10.1016/ 0304-3932(88)90168-7

Lucas RE (1993) Making a miracle. Econometrica 61:251-272. doi:10.2307/2951551

Machlup F (1962) The production and distribution of knowledge in the United States. University Press, Princeton

Mathur VK (1999) Human-capital-based strategy for regional economic development. Econ Dev Q XIII:203-216. doi:10.1177/089124249901300301

McCann P (2004) Urban scale economies: statics and dynamics. In: Capello R, Nijkamp P (eds) Urban dynamics and growth. Elsevier, Amsterdam, pp 31-56

McCloskey DN, Klamer A (1995) One quarter of GDP is persuasion. Am Econ Rev 85:191-195

Neale MC, Boker SM, Xie G, Maes HH (2003) Mx: statistical modeling, 6th edn. Department of Psychiatry, Richmond

OECD (2003) Science. Technology and Industry Scoreboard, Paris

Oud JHL, Folmer H (2008) A structural equation approach to models with spatial dependence. Geogr Anal 40:152-166

Van Oort FG (2004) Urban growth and innovation. Ashgate, Aldershot

Van Oort FG, Burger M, Raspe O (2008) Inter-firm relations and economic clustering in the Dutch Randstad region. In: Blien U, Maier G (eds) The economics of regional clusters. Networks, technology and policy. Edward Elgar, Cheltenham, pp 145-165

Parr JB (2005) Perspectives on the city-region. Reg Stud 39:555-566. doi:10.1080/00343400500151798

Raspe O, Van Oort FG (2006) The knowledge economy and urban economic growth. Eur Plann Stud 14:1209-1234. doi:10.1080/09654310600933322

Rosenthal SS, Strange W (2004) Evidence on the sources of agglomeration economies. In: Henderson JV, Thisse JF (eds) Handbook of regional and urban economics. Elsevier, Amsterdam, pp 2119-2172

Saviotti PP, Pyka A (2004) Economic development, variety and employment creation. Rev Econ 55:10231059

Surinach J, Moreno R, Vaya E (eds) (2007) Knowledge externalities, innovation clusters and regional development. Edward Elgar, Cheltenham

Thissen MJPM (2005) The size of agglomeration economies in the Netherlands. An analysis with a spatial CGE-model. Working paper. RPB, The Hague

Wallsten SJ (2001) An empirical test of geographic knowledge spillovers using geographic information systems and firm-level data. Reg Sci Urban Econ 31:571-599

Warsh D (2006) Knowledge and the wealth of nations. W.W. Norton, New York

Wever E, Stam E (1999) Clusters of high-technology SME's: the Dutch case. Reg Stud 33:391-400 